\title{
Computational Investigations of Iodine Oxides
}

\author{
Ashutosh Misra ${ }^{\dagger}$ and Paul Marshall*,* \\ Air Liquide Electronics Chemical and Services, Inc., 13546 North Central Expressway, MS 301, \\ Dallas, Texas 75243, and Department of Chemistry, University of North Texas, P.O. Box 305070, \\ Denton, Texas 76203
}

Received: June 22, 1998; In Final Form: August 21, 1998

\begin{abstract}
Isomers of $\mathrm{IO}_{2}, \mathrm{I}_{2} \mathrm{O}$, and $\mathrm{I}_{2} \mathrm{O}_{2}$ have been characterized by ab initio methods. Vibrational frequencies and geometries were obtained at the MP2/6-31G(d) and MP2/6-311+G(3df) levels of theory, respectively. The thermochemistry was derived using approximate $\operatorname{QCISD}(\mathrm{T}) / 6-311+\mathrm{G}(3 \mathrm{df})($ Gaussian-2) energies coupled with isodesmic reactions. Computed values of $\Delta_{\mathrm{f}} \mathrm{H}_{298}$ for these molecules are the following (in kJ mol${ }^{-1}$ ): OIO, 76.7; IOO, 96.6; IIO, 134.1; IOI, 92.4; IOOI, 156.8; IIO $_{2}$, 103.0; IOIO, 124.2; OIIO, 224.0. Uncertainties are discussed in the text. The results are compared with some previous empirical estimates and are employed in a QRRK analysis to interpret the IO + IO reaction: favorable products include I + OIO.
\end{abstract}

\section{Introduction}

Iodine oxides have been implicated in the atmospheric chemistry of iodine, ${ }^{1,2}$ in the behavior of iodine-ozone mixtures, ${ }^{3}$ and in the mechanism of oxygen-iodine lasers. ${ }^{4} \mathrm{~A}$ recent review ${ }^{5}$ has drawn attention to the lack of information about any gas-phase iodine oxides except the simplest, IO, which is now well-characterized, and OIO, whose electronic and vibrational spectra have been obtained both in the gas phase $\mathrm{e}^{6}$ and in a frozen argon matrix. ${ }^{7}$ There are apparently no structural, vibrational, or thermochemical measurements available for other iodine oxides, and indeed the existence of some is speculative. The aim of the present work is to address this deficiency via ab initio analysis of the oxides $\mathrm{IO}_{2}, \mathrm{I}_{2} \mathrm{O}$, and $\mathrm{I}_{2} \mathrm{O}_{2}$ and their isomers. The thermochemistry of eight oxides is presented, and all are found to be thermodynamically unstable with respect to the elements at $298 \mathrm{~K}$. However, each molecule is stable with respect to breaking a single bond, and therefore, they may play roles as transient intermediates. The implications of some of the derived bond dissociation enthalpies for the kinetics of formation and loss of iodine oxides are assessed. The results should aid interpretation of the environmental fate of iodine. This has recently become of increasing interest, following the suggestion that iodine compounds may influence the lower stratosphere, ${ }^{1,2}$ and in the light of the possible use of $\mathrm{CF}_{3} \mathrm{I}$ and similar compounds as non global warming and ozonefriendly replacements for halon fire suppression agents ${ }^{8}$ and perfluorocarbon plasma etchants for silicon wafers. ${ }^{9,10}$

\section{Methodology}

All computations were made with the Gaussian 94 program suite. ${ }^{11}$ Gaussian-2 (G2) theory, ${ }^{12}$ as extended to iodinecontaining species by Glukhovstev et al., ${ }^{13}$ was applied to $\mathrm{I}_{x} \mathrm{O}_{y}$. All-electron basis sets were employed in non-relativistic calculations, and earlier good accord with experimental results suggests that relativistic effects are either small or cancel. ${ }^{13}$ The first steps in standard G2 theory are to compute the geometry at the MP2=FULL/6-31G(d) and the frequencies at the HF/6-31G(d)

\footnotetext{
Air Liquide Electronics Chemical and Services, Inc.

$\doteqdot$ University of North Texas.
}

levels of theory, respectively. Whereas such results are usually in good accord with experimental measurements, as we discussed earlier ${ }^{14}$ this is clearly not the case for a test molecule, IO. We have employed MP2 $=\mathrm{FC} / 6-311+\mathrm{G}(3 \mathrm{df})$ calculations for the geometries because this level of theory gave better accord with the experimental $\mathrm{IO}$ bond length ${ }^{15}$ than results obtained with smaller basis sets or other electron correlation treatments, including B3LYP and QCISD(T). ${ }^{14}$ Frequency calculations at this level are too computationally demanding, and instead $\mathrm{MP} 2=\mathrm{FC} / 6-31 \mathrm{G}(\mathrm{d})$ values scaled by a standard factor ${ }^{16}$ of 0.9646 were employed.

Next, a series of calculations were carried out at each $\mathrm{MP} 2=\mathrm{FC} / 6-311+\mathrm{G}(3 \mathrm{df})$-optimized geometry to obtain the single-point energy at a high level of theory. Approximate QCISD(T)/6-311+G(3df) results were obtained via the G2$(\mathrm{ZPE}=\mathrm{MP} 2)$ methodology of Curtiss et al. ${ }^{16}$ Their procedure is modified here by the use of geometries obtained with a larger basis set and by the use of MP2 $=\mathrm{FC} / 6-31 \mathrm{G}(\mathrm{d})$ vibrational frequencies obtained with the frozen core approximation. The vibrational frequencies were also employed to calculate the enthalpy corrections, $H_{298}-H_{0}$, and other thermodynamic functions.

The enthalpy of formation of IOI was derived via the computed $0 \mathrm{~K}$ reaction enthalpy $\Delta H_{0}$ for the isodesmic reaction

$$
\mathrm{IOI}+\mathrm{H}_{2} \mathrm{O} \rightarrow 2 \mathrm{HOI}
$$

coupled with the known $\Delta_{\mathrm{f}} \mathrm{H}_{0}$ of $\mathrm{H}_{2} \mathrm{O}^{15}$ and $\mathrm{HOI}$ (see below). $\Delta_{\mathrm{f}} H_{0}$ (IIO) was obtained from $\Delta_{\mathrm{f}} H_{0}$ (IOI) together with the G2 energy difference between the two isomers. $\Delta_{\mathrm{f}} H_{298}$ values were obtained via the relation $\Delta_{\mathrm{f}} H_{298}=\Delta_{\mathrm{f}} H_{0}+\left(H_{298}-H_{0}\right)_{\text {compound }}$

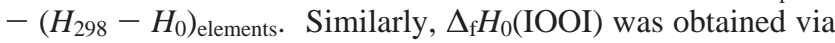
the isodesmic process

$$
\mathrm{IOOI}+2 \mathrm{H}_{2} \mathrm{O} \rightarrow 2 \mathrm{HOI}+\mathrm{H}_{2} \mathrm{O}_{2}
$$

and the known $\Delta_{\mathrm{f}} \mathrm{H}_{0}$ of $\mathrm{H}_{2} \mathrm{O}_{2},{ }^{15} \mathrm{H}_{2} \mathrm{O}$, and HOI. The formation enthalpies of other $\mathrm{I}_{2} \mathrm{O}_{2}$ isomers were assessed through $\mathrm{G} 2$ energies relative to IOOI. The thermochemistry of OIO was derived from its experimentally known electron affinity ${ }^{17}$ combined with the enthalpy of formation of the anion $\mathrm{OIO}^{-}$, 
TABLE 1: Comparison of Computed and Experimental Bond Lengths and Frequencies

\begin{tabular}{|c|c|c|c|c|}
\hline \multirow[b]{2}{*}{ bond } & \multicolumn{2}{|c|}{ length $/ 10^{-10} \mathrm{~m}$} & \multicolumn{2}{|c|}{ frequency $/ \mathrm{cm}^{-1}$} \\
\hline & $\begin{array}{c}\mathrm{MP} 2=\mathrm{FC} / \\
6-311+\mathrm{G}(3 \mathrm{df})\end{array}$ & $\operatorname{obsd}^{a}$ & $\begin{array}{l}\mathrm{MP} 2=\mathrm{FC} / \\
6-31 \mathrm{G}(\mathrm{d})^{b}\end{array}$ & $\operatorname{obsd}^{a}$ \\
\hline $\mathrm{I}-\mathrm{I}$ & 2.680 & 2.665 & 217 & 213 \\
\hline $\mathrm{I}-\mathrm{O}$ & 1.888 & 1.868 & 724 & 673 \\
\hline $\mathrm{O}-\mathrm{O}$ & 1.219 & 1.208 & 1360 & 1556 \\
\hline $\mathrm{HO}-\mathrm{OH}$ & 1.444 & 1.464 & 896 & 875 \\
\hline
\end{tabular}

evaluated via $\Delta H_{0}$ for the congeneric reaction

$$
\mathrm{OIO}^{-}+\mathrm{ClO} \rightarrow \mathrm{OClO}^{-}+\mathrm{IO}
$$

extrapolated to $298 \mathrm{~K}$ via $H_{298}-H_{0}$ values. This procedure avoids the need for explicit calculation of the spin-orbit coupling term in OIO, which instead is included in its measured electron affinity. $\Delta_{\mathrm{f}} \mathrm{H}_{298}$ of $\mathrm{IO},{ }^{18} \mathrm{ClO},{ }^{19}$ and $\mathrm{OClO}^{19}$ were taken from the literature. The latter quantity, combined with the electron affinity of $\mathrm{OClO},{ }^{17}$ yields $\Delta H_{298}\left(\mathrm{OClO}^{-}\right)$. The "ion convention" was employed for the thermochemistry. ${ }^{20}$

IOO was found to be a very loose adduct of an I atom to $\mathrm{O}_{2}$, and therefore its thermochemistry was assessed from the energy relative to $\mathrm{I}+\mathrm{O}_{2}$.

We expect errors in the isodesmic reactions arising from deficiencies in the vibrational frequencies, basis sets, and correlation corrections mostly to cancel, so that the largest contribution to the uncertainty of the resulting thermochemistry comes from the uncertainty in $\Delta_{\mathrm{f}} H_{0}(\mathrm{HOI})$. We have employed our estimated value ${ }^{21}$ of $-64.9 \pm 5.4 \mathrm{~kJ} \mathrm{~mol}^{-1}$, which compares well with a value of $-55.2 \pm 6.9 \mathrm{~kJ} \mathrm{~mol}^{-1}$ computed by Hassanzadeh and Irikura. ${ }^{22}$ Propagation of its uncertainty through eqs $1-3$ leads to an uncertainty of $\pm 5.4 \mathrm{~kJ} \mathrm{~mol}^{-1}$ for OIO and $\pm 10.8 \mathrm{~kJ} \mathrm{~mol}^{-1}$ for the molecules containing two iodine atoms. Uncertainties in other ancillary quantities are negligible. This is a lower limit, which does not include allowance for errors in the relative energies for isomers. More conservative limits of $\pm 15 \mathrm{~kJ} \mathrm{~mol}^{-1}$ are suggested provisionally for all of the species until the accuracy of the calculations can be tested against experiment.

\section{Results and Discussion}

A comparison between experimental and computed results for $\mathrm{I}-\mathrm{O}, \mathrm{I}-\mathrm{I}$, and $\mathrm{O}-\mathrm{O}$ bonds is given in Table 1 , which indicates good accord for the known bond lengths and moderate accord for the frequencies at the theoretical levels employed. These frequencies are used to derive thermodynamic functions and zero-point energies, and an error of $100 \mathrm{~cm}^{-1}$ corresponds to only $0.6 \mathrm{~kJ} \mathrm{~mol}^{-1}$ in zero-point energy. Figures 1 and 2 show the computed geometries of the iodine oxides $\mathbf{1 - 8}$, and the computed frequencies are listed in Table 2. It should be noted that the ab initio frequencies for the anions $\mathrm{OClO}^{-}$and $\mathrm{OIO}^{-}$are too high (by around 16\%) by comparison with measured symmetric stretches of $774 \pm 25$ and $675 \pm 25 \mathrm{~cm}^{-1}$, respectively. ${ }^{17}$ The computed energies and thermochemistry for iodine oxides and ancillary species are listed in Table 3.

3.1. $\mathrm{IO}_{2}$ Species. The $\mathrm{IO}_{2}$ system has been studied recently by matrix isolation methods. Condensation of flash-pyrolyzed iodine-oxygen mixtures by Maier and Bothur led to a species with a peak UV absorbance of about $250 \mathrm{~nm}$, attributed to IOO, which reversibly photoisomerized to a species attributed to OIO. ${ }^{7}$ The IR spectrum of OIO showed peaks for asymmetric and symmetric stretching of 800 and $768 \mathrm{~cm}^{-1}$, respectively. Earlier

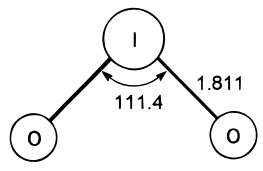

(1)

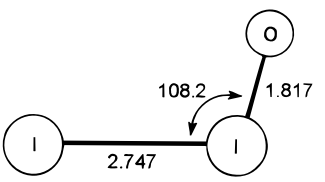

(3)

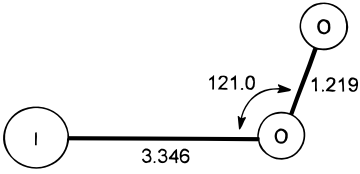

(2)

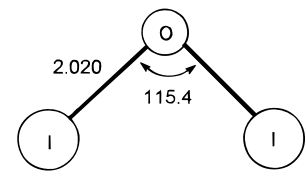

Figure 1. $\mathrm{MP} 2=\mathrm{FC} / 6-311+\mathrm{G}(3 \mathrm{df})$ geometries of triatomic iodine oxides with bond lengths in $10^{-10} \mathrm{~m}$ and angles in degrees. (1) $C_{2 v}$ OIO, ${ }^{2} \mathrm{~B}_{1}$. (2) $C_{S} \mathrm{IOO},{ }^{2} \mathrm{~A}^{\prime \prime}$. (3) $C_{S} \mathrm{IIO},{ }^{1} \mathrm{~A}^{\prime}$. (4) $C_{2 v} \mathrm{IOI},{ }^{1} \mathrm{~A}_{1}$.

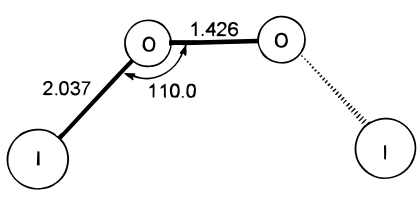

(5)

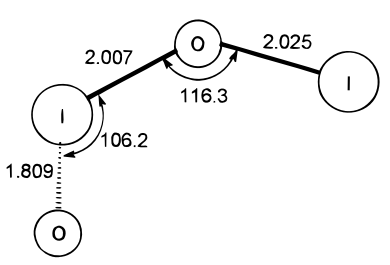

(7)

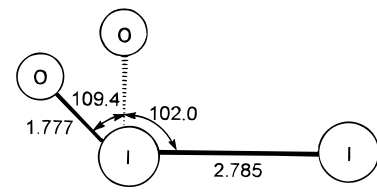

(6)

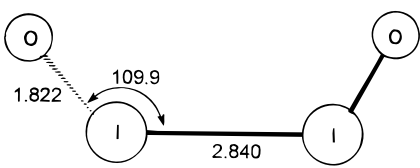

Figure 2. $\mathrm{MP} 2=\mathrm{FC} / 6-311+\mathrm{G}(3 \mathrm{df})$ geometries of tetratomic iodine oxides with bond lengths in $10^{-10} \mathrm{~m}$ and angles in degrees. (5) $C_{2}$ IOOI, ${ }^{1} \mathrm{~A}$, dihedral $86.0^{\circ}$. (6) $C_{S} \mathrm{IIO}_{2},{ }^{1} \mathrm{~A}^{\prime}$. (7) $C_{1} \mathrm{IOIO},{ }^{1} \mathrm{~A}$, dihedral $67.0^{\circ}$. (8) $C_{2}$ OIIO, ${ }^{1} \mathrm{~A}$, dihedral $90.1^{\circ}$.

TABLE 2: Frequencies at the MP2 $=$ FC/6-31G(d) Level (Scaled by 0.9646 )

\begin{tabular}{|c|c|c|}
\hline oxide & state & frequencies $/ \mathrm{cm}^{-1} a$ \\
\hline $\mathrm{OIO}$ & ${ }^{2} \mathrm{~B}_{1}$ & $\mathrm{~B}_{2} 836$ (273); $\mathrm{A}_{1} 797$ (5), 251 (22) \\
\hline $\mathrm{IOO}^{b}$ & ${ }^{2} A^{\prime \prime}$ & $\mathrm{A}^{\prime} 1610(115), 198(0.1), 81(0.2)$ \\
\hline IIO & ${ }^{1} \mathrm{~A}^{\prime}$ & $\mathrm{A}^{\prime} 909(153), 178(30), 131$ (5) \\
\hline IOI & ${ }^{1} \mathrm{~A}_{1}$ & $\mathrm{~B}_{2} 597(18) ; \mathrm{A}_{1} 422(2), 126(0.3)$ \\
\hline IOOI & ${ }^{1} \mathrm{~A}$ & $\begin{array}{l}\text { A } 714(26), 519(12), 505(2), 303(0.9), 195(0.0) \text {, } \\
58(0.4)\end{array}$ \\
\hline $\mathrm{IIO}_{2}$ & ${ }^{1} \mathrm{~A}^{\prime}$ & $\begin{array}{l}\text { A }^{\prime \prime} 968(122), 133(2) ; A^{\prime} 950(86), 290(22), \\
\quad 213(59), 134(13)\end{array}$ \\
\hline $\mathrm{IOIO}$ & ${ }^{1} \mathrm{~A}$ & A $928(84), 561(80), 398$ (35), $206(12), 120(4), 50$ (6) \\
\hline OIIO & ${ }^{1} \mathrm{~A}$ & $\begin{array}{l}\text { В } 901(368), 116(11) \text {; A } 917 \text { (39), } 130(1.1) \text {, } \\
\quad 77(0.4), 62(10)\end{array}$ \\
\hline $\mathrm{OClO}^{-}$ & ${ }^{1} \mathrm{~A}_{1}$ & $\mathrm{~B}_{2} 915$ (21); $\mathrm{A}_{1} 853(18), 361$ (18) \\
\hline $\mathrm{OIO}^{-}$ & ${ }^{1} \mathrm{~A}_{1}$ & $\mathrm{~B}_{2} 770(182) ; \mathrm{A}_{1} 760(47), 244$ (26) \\
\hline
\end{tabular}

${ }^{a}$ Frequencies grouped by symmetry and IR intensities, in $\mathrm{km} \mathrm{mol}^{-1}$, given in parentheses. ${ }^{b}$ Unscaled B3LYP/6-311G(d,p) values.

gas-phase assignments derived via photoelectron spectroscopy of $\mathrm{OIO}^{-}$by Gilles et al. ${ }^{17}$ are $765 \mathrm{~cm}^{-1}$ for the symmetric stretch and $192 \mathrm{~cm}^{-1}$ for bending, while Himmelmann et al. ${ }^{6}$ recently obtained 631 and $177 \mathrm{~cm}^{-1}$ from the visible spectrum. The computed values (Table 2) are in fair accord with these measurements and are consistent with an uncertainty in the computed frequencies of up to $200 \mathrm{~cm}^{-1}$. No bound IOO 
TABLE 3: Energies of $I_{x} O_{y}$ Isomers and Ancillary Species

\begin{tabular}{|c|c|c|c|c|c|c|}
\hline species & $\mathrm{G} 2(\mathrm{ZPE}=\mathrm{MP} 2) / \mathrm{au}^{a}$ & $\Delta_{\mathrm{f}} H_{0} / \mathrm{kJ} \mathrm{mol}^{-1}$ & $\Delta_{\mathrm{f}} H_{298} / \mathrm{kJ} \mathrm{mol}^{-1}$ & $H_{298}-H_{0} / \mathrm{kJ} \mathrm{mol}^{-1}$ & $C_{\mathrm{p}, 298} / \mathrm{J} \mathrm{K}^{-1} \mathrm{~mol}^{-1}$ & $S_{298} / \mathrm{J} \mathrm{K}^{-1} \mathrm{~mol}^{-1}$ \\
\hline $\mathrm{OIO}$ & -7067.15393 & 80.4 & 76.7 & 11.6 & 45.9 & 279.9 \\
\hline IOO & $-7067.14174^{b}$ & 104.1 & 96.6 & 13.4 & 49.4 & 308.4 \\
\hline IIO & -13909.09478 & 138.2 & 134.1 & 13.4 & 51.2 & 317.8 \\
\hline IOI & -13909.11048 & 97.0 & 92.4 & 12.9 & 51.6 & 306.5 \\
\hline IOOI & -13984.16287 & 162.7 & 156.8 & 16.1 & 69.8 & 337.0 \\
\hline $\mathrm{IIO}_{2}$ & -13984.18341 & 108.7 & 103.0 & 16.2 & 67.6 & 339.9 \\
\hline IOIO & -13984.17557 & 129.3 & 124.2 & 16.8 & 70.1 & 349.7 \\
\hline $\mathrm{OIIO}$ & -13984.13804 & 227.8 & 224.0 & 18.0 & 70.0 & 356.3 \\
\hline $\mathrm{OIO}^{-c}$ & -7067.24906 & & -171.9 & 11.7 & & \\
\hline $\mathrm{OClO}^{-d}$ & -609.91634 & & $-111.9^{e}$ & 11.1 & & \\
\hline $\mathrm{IO}^{f}$ & -6992.05805 & $117.8^{g}$ & $115.9^{g}$ & $9.0^{h}$ & & $239.6^{h}$ \\
\hline $\mathrm{ClO}^{i}$ & -534.75790 & & $102.1^{j}$ & $9.5^{h}$ & & \\
\hline $\mathrm{H}_{2} \mathrm{O}_{2}$ & -151.36917 & $-129.9^{h}$ & & & & \\
\hline $\mathrm{H}_{2} \mathrm{O}$ & -76.33327 & $-238.9^{h}$ & & & & \\
\hline HOI & -6992.71957 & $-64.9^{k}$ & & & & \\
\hline
\end{tabular}

${ }^{a} 1 \mathrm{au} \approx 2625 \mathrm{~kJ} \mathrm{~mol}^{-1}$. Calculated at MP2 $=\mathrm{FC} / 6-311+\mathrm{G}(3 \mathrm{df}, 2 \mathrm{p})$ geometries with zero-point energies at MP2=FC/6-31G(d). ${ }^{b} \mathrm{Unscaled} \mathrm{B} 3 \mathrm{LYP} /$ $6-311 \mathrm{G}(\mathrm{d})$ frequencies used. ${ }^{c}$ Bond length $1.858 \times 10^{-10} \mathrm{~m}$ and angle $109.4^{\circ}$. Ion convention used for thermochemistry. ${ }^{d}$ Bond length $1.549 \times$ $10^{-10} \mathrm{~m}$ and angle $113.8^{\circ}$. Ion convention used for thermochemistry. ${ }^{e}$ References 17 and $19 .{ }^{f}$ Bond length $1.888 \times 10^{-10} \mathrm{~m}$, frequency $724 \mathrm{~cm}^{-1}$ and includes an empirical spin-orbit correction of -0.00476 au (half the experimental ${ }^{2} \Pi_{3 / 2}-{ }^{2} \Pi_{1 / 2}$ splitting). ${ }^{g}$ Reference $18 .{ }^{h}$ Reference 15 . ${ }^{i}$ Bond length $1.549 \times 10^{-10} \mathrm{~m}$, frequency $825 \mathrm{~cm}^{-1}$ and includes an empirical spin-orbit correction of -0.00072 au (half the experimental ${ }^{2} \Pi_{3 / 2}$ $-{ }^{2} \Pi_{1 / 2}$ splitting). ${ }^{j}$ Reference $19 .{ }^{k}$ Reference 14.

species was located at the MP2 $=$ FULL/6-31G(d) level of theory, although a very loose adduct with $r(\mathrm{I}-\mathrm{O})=2.870 \times 10^{-10} \mathrm{~m}$ was found using density functional theory (B3LYP/6-311G(d)). As seen on Figure 1, use of MP2 $=\mathrm{FC} / 6-311+\mathrm{G}(3 \mathrm{df})$ theory led to an even greater $\mathrm{I}-\mathrm{O}$ distance, and at the $\mathrm{G} 2$ level IOO appears to be bound by only $3.1 \mathrm{~kJ} \mathrm{~mol}^{-1}$ relative to $\mathrm{I}+\mathrm{O}_{2}$ at $0 \mathrm{~K}$. This binding energy is probably not very accurate. There is significant spin contamination $\left(\left\langle S^{2}\right\rangle=1.60\right)$ in the IOO wavefunction and a possibility of basis set superposition error. A crude estimate of the latter effect was obtained via the counterpoise method at the HF/6-311+G(3df,2p) level, where it was found that the $\mathrm{I}$ and $\mathrm{O}_{2}$ fragments were stabilized by 1.6 $\mathrm{kJ} \mathrm{mol}^{-1}$ when their energies were evaluated with the combined IOO basis functions. Clearly the interaction between $\mathrm{I}$ and $\mathrm{O}_{2}$ is weak. The $\mathrm{I}-\mathrm{O}$ distance approximately equals the sum of the $\mathrm{I}$ and $\mathrm{O}$ van der Waals radii and is consistent with the speculation by Maier and Bothur that IOO might be described as a complex between $\mathrm{I}$ and $\mathrm{O}_{2} \cdot{ }^{7}$ However, it is not clear that such a weak interaction could perturb the $\mathrm{I}$ and $\mathrm{O}_{2}$ orbitals sufficiently to yield the observed UV spectrum. Another, as yet unidentified, species may be involved. Further evidence that $\mathrm{I}$ and $\mathrm{O}_{2}$ do not bond strongly comes from the kinetics of I atom recombination in the presence of various buffer gases, M. If $\mathrm{I}$ and $\mathrm{O}_{2}$ bonded readily at room temperature, as do I and NO, then the rate of recombination would be dramatically enhanced via the radical complex mechanism

$$
\begin{gathered}
\mathrm{I}+\mathrm{M} \rightleftharpoons \mathrm{IM} \\
\mathrm{I}+\mathrm{IM} \rightarrow \mathrm{I}_{2}+\mathrm{M}
\end{gathered}
$$

At room temperature, the collision efficiencies for I atom recombination in the presence of $\mathrm{M}=\mathrm{Ar}, \mathrm{O}_{2}$, and $\mathrm{NO}$ are in the approximate ratio $1: 2: 10^{4},{ }^{23}$ indicating no special enhancement by oxygen (unlike NO), and thus that IOO is not easily formed. The NIST-JANAF empirically estimated $\Delta_{\mathrm{f}} H_{298}$ for IOO is $116.5 \pm 40 \mathrm{~kJ} \mathrm{~mol}^{-1}, 5$ in accord with but $20 \mathrm{~kJ} \mathrm{~mol}^{-1}$ more positive than our estimate in Table 3 . For OIO the empirical NIST-JANAF ${ }^{5} \Delta_{\mathrm{f}} H_{298}$ of $159.3 \pm 25 \mathrm{~kJ} \mathrm{~mol}^{-1}$ lies $80 \mathrm{~kJ} \mathrm{~mol}^{-1}$ above our ab initio value, which we believe to be more accurate. In particular, our calculations show that OIO is stable with respect to $\mathrm{I}+\mathrm{O}_{2}$. The $\left\langle S^{2}\right\rangle$ values for $\mathrm{ClO}$ and IO were 0.77 and 0.78 , respectively, so that spin contamination has a negligible impact on the energy of reaction 3.
The OI-O bond dissociation enthalpy at $298 \mathrm{~K}$ derived via $\Delta_{\mathrm{f}} \mathrm{H}_{298}(\mathrm{IO})^{18}$ is $288 \mathrm{~kJ} \mathrm{~mol}^{-1}$, a value which implies that OIO could be formed exothermically by abstraction reactions of IO with several atmospheric oxidants including $\mathrm{O}_{3}, \mathrm{HO}_{2}, \mathrm{~N}_{2} \mathrm{O}$, and $\mathrm{NO}_{3}$. Such reactions may have significant barriers, and it is noted that the reactions of $\mathrm{IO}$ with $\mathrm{O}_{3}$ and $\mathrm{N}_{2} \mathrm{O}$ are very slow. ${ }^{24}$ Oxygen atom abstraction from $\mathrm{NO}_{2}$ is endothermic by $18 \mathrm{~kJ}$ $\mathrm{mol}^{-1}$ at $298 \mathrm{~K}$.

3.2. $\mathbf{I}_{2} \mathrm{O}$ Species. Two isomers are illustrated in Figure 1. Because $\mathrm{I}-\mathrm{O}$ bonds are stronger than $\mathrm{I}-\mathrm{I}$ bonds, the $\mathrm{IOI}$ isomer is more stable than the IIO configuration. There are no measurements on these molecules to compare with our calculations, although the NIST-JANAF tables contain empirical estimates. ${ }^{5}$ The frequencies and geometry are close to our computed values, while the ab initio values of $\Delta_{\mathrm{f}} H_{298}$ for IOI and IIO (Table 3) lie near the lower and upper limits of the empirical estimates of $119.5 \pm 25$ and $106.7 \pm 40 \mathrm{~kJ} \mathrm{~mol}^{-1}$, respectively. ${ }^{5}$ The NIST-JANAF tables assign the ground state of $\mathrm{IIO}$ as a triplet, ${ }^{5}$ in disagreement with our calculations. At the singlet $\mathrm{A}^{\prime}$ IIO geometry, the lowest lying triplet state, $\mathrm{A}^{\prime \prime}$, is found at the QCISD(T)/6-311G(d) level to lie $124 \mathrm{~kJ} \mathrm{~mol}^{-1}$ above the singlet state. This discrepancy accounts for much of the $13 \mathrm{~J} \mathrm{~K}^{-1} \mathrm{~mol}^{-1}$ difference between our entropy (Table 3) and the published value. ${ }^{5}$ We were unable to locate a ${ }^{3} \mathrm{~A}^{\prime \prime}$ minimum at the HF/6-31G(d) level, and this state may not be bound.

3.3. $\mathrm{I}_{2} \mathrm{O}_{2}$ Species. Four bound isomers are illustrated in Figure 2, and the relative stabilities are shown in Figure 3. The most stable isomer is $\mathrm{IIO}_{2}$, which has a pair of the shortest $\mathrm{I}-\mathrm{O}$ bonds found in this study, $r(\mathrm{I}-\mathrm{O})=1.78 \times 10^{-10} \mathrm{~m}$, and the highest $\mathrm{I}-\mathrm{O}$ stretching frequencies of about $960 \mathrm{~cm}^{-1}$, suggesting that these may be double bonds. The iodinated analog of hydrogen peroxide, IOOI, presumably has single $\mathrm{I}-\mathrm{O}$ bonds, and $r(\mathrm{I}-\mathrm{O})=2.04 \times 10^{-10} \mathrm{~m}$ with lower $\mathrm{I}-\mathrm{O}$ stretching frequencies of about $510 \mathrm{~cm}^{-1}$. Many of the $\mathrm{I}-\mathrm{O}$ bond lengths and frequencies here fall between these limits, suggesting partial multiple bond character in these iodine oxides.

There appear to be no literature data for these oxides, although they have been discussed in the context of the kinetics of the $\mathrm{IO}+\mathrm{IO}$ self reaction

$$
\mathrm{IO}+\mathrm{IO} \rightarrow \text { products }
$$

which have been measured several times, with IO generation 


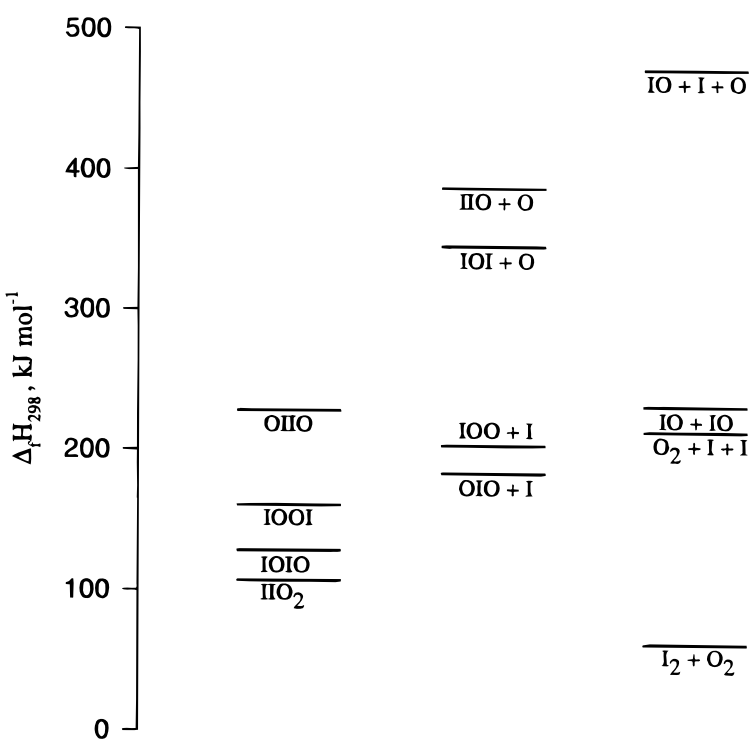

Figure 3. Enthalpies of formation of combinations of two oxygen and two iodine atoms at $298 \mathrm{~K}$.

TABLE 4: Estimated Arrhenius Parameters for Dissociation Reactions at the High-Pressure Limit at $298 \mathrm{~K}$

\begin{tabular}{ccc}
\hline reaction & $A / \mathrm{s}^{-1}$ & $E_{\mathrm{a}} / \mathrm{kJ} \mathrm{mol}^{-1}$ \\
\hline $\mathrm{IOIO} \rightarrow 2 \mathrm{IO}$ & $3.8 \times 10^{16}$ & 110.1 \\
$\mathrm{IOIO} \rightarrow \mathrm{I}+$ OIO & $4.2 \times 10^{15}$ & 61.8 \\
$\mathrm{IIO}_{2} \rightarrow \mathrm{I}+$ OIO & $1.4 \times 10^{16}$ & 77.3
\end{tabular}

from the reactions $\mathrm{I}+\mathrm{O}_{3}, \mathrm{O}+\mathrm{I}_{2}$, and $\mathrm{O}+\mathrm{CF}_{3} \mathrm{I}^{3,25-30}$ The possible products $\mathrm{I}_{2}+\mathrm{O}_{2}$ and $\mathrm{I}+\mathrm{I}+\mathrm{O}_{2}$ are thermodynamically accessible but their contributions have been found to be small. ${ }^{3,28}$ As seen in Figure 3, the four $\mathrm{I}_{2} \mathrm{O}_{2}$ isomers are thermodynamically plausible products of reaction 4 . Formation of $\mathrm{IIO}_{2}$ would require extensive bond rearrangement, but the next most stable species, IOIO, can be formed in an initially excited state by direct $\mathrm{IO}+\mathrm{IO}$ addition. Excited $\mathrm{IOIO}^{*}$ may either be stabilized by collision with the bath gas $\mathrm{M}$, or may fragment, and the most stable fragmentation products are $\mathrm{OIO}+\mathrm{I}$ :

$$
\begin{gathered}
\mathrm{IO}+\mathrm{IO} \rightleftharpoons \mathrm{IOIO}^{*} \rightarrow \mathrm{OIO}+\mathrm{I} \\
(+\mathrm{M}) \rightarrow \mathrm{IOIO}(+\mathrm{M})
\end{gathered}
$$

A QRRK analysis ${ }^{31,32}$ of these competing pathways was carried out with assumed Lennard-Jones parameters for IOIO of $\sigma=$ $5 \times 10^{-10} \mathrm{~m}$ and $\epsilon / k_{\mathrm{B}}=500 \mathrm{~K}$. A rate constant for radical + radical reactions forming excited intermediates (i.e., the highpressure limiting value) of $10^{-10}$ molecule ${ }^{-1} \mathrm{~cm}^{3} \mathrm{~s}^{-1}$ was employed, which is roughly equal to the rate constants measured for $\mathrm{IO}+\mathrm{IO}, \mathrm{O}+\mathrm{IO}$, and $\mathrm{O}+\mathrm{I}_{2}{ }^{28}$ The Arrhenius parameters employed for the unimolecular dissociation steps at $298 \mathrm{~K}$ are listed in Table 4 and were derived as follows. Activation energies for dissociation steps were set equal to the endothermicity plus $R T$, and the pre-exponential factors were derived from microscopic reversibility and equilibrium constants on the basis of our computed enthalpy and entropy changes. The QRRK analysis indicates that, for pressures of up to 1 bar of $\mathrm{N}_{2}$ bath gas, the dominant channel at $298 \mathrm{~K}$ will be the pressureindependent formation of $\mathrm{OIO}+\mathrm{I}$, unless there is a significant barrier to fragmentation of IOIO beyond the endothermicity. Preliminary searches of the B3LYP/6-31G(d) potential energy surface did not reveal such a barrier.

The species IOOI and OIIO are also possible products, but are less tightly bound than IOIO because of their weak central bonds, and at room temperature are not stable sinks for $\mathrm{IO}+$ IO. Any initially excited IOOI formed from $\mathrm{IO}+\mathrm{IO}$ recombination is likely to decompose immediately to $\mathrm{I}+\mathrm{IOO}$ and, as indicated above, IOO is weakly bound, so that IOOI might provide a path for a $2 \mathrm{I}+\mathrm{O}_{2}$ product channel.

IOIO could be formed via

$$
\mathrm{OIO}+\mathrm{I}+\mathrm{N}_{2} \rightarrow \mathrm{IOIO}+\mathrm{N}_{2}
$$

The predicted kinetics are close to third order for up to 1 bar of $\mathrm{N}_{2}$ at $298 \mathrm{~K}$, and the predicted rate constant is $7.6 \times 10^{-32}$ molecule $\mathrm{e}^{-2} \mathrm{~cm}^{6} \mathrm{~s}^{-1}$. Changing the $\mathrm{I}-\mathrm{OIO}$ bond strength at 298 $\mathrm{K}$ of $59 \mathrm{~kJ} \mathrm{~mol}^{-1}$ by $\pm 15 \mathrm{~kJ} \mathrm{~mol}^{-1}$ changes $k_{5}$ by about a factor of 3, which is an approximate measure of the uncertainty in this rate constant arising from the thermochemistry. At 1 bar of $\mathrm{N}_{2}$ the lifetime of IOIO with respect to dissociation to OIO $+\mathrm{I}$ is predicted to be about $1 \mathrm{~ms}$, so IOIO is hardly stable at ambient conditions, although of course its lifetime will increase at lower temperatures and lower pressures. The channel

$$
\mathrm{IOIO}+\mathrm{N}_{2} \rightarrow \mathrm{IO}+\mathrm{IO}+\mathrm{N}_{2}
$$

is predicted to show second-order kinetics for $\mathrm{N}_{2}$ of up to 1 bar, with $k_{6}=2.1 \times 10^{-24}$ molecule $\mathrm{e}^{-1} \mathrm{~cm}^{3} \mathrm{~s}^{-1}$. Variation of the IO-IO bond strength of $108 \mathrm{~kJ} \mathrm{~mol}^{-1}$ by $\pm 15 \mathrm{~kJ} \mathrm{~mol}^{-1}$ leads to changes of a factor of 2 in $k_{6}$. The corresponding reverse rate constant $k_{-6}$ is $1.1 \times 10^{-31}$ molecule $\mathrm{cm}^{6} \mathrm{~s}^{-1}$. This compares reasonably with the apparent low-pressure limiting recombination rate constant obtained by Jenkin and $\mathrm{Cox}^{27}$ of about $(4 \pm 2) \times 10^{-31}$ molecule ${ }^{-2} \mathrm{~cm}^{6} \mathrm{~s}^{-1}$. However, they observed significant fall-off at 0.5 bar, not reproduced in our calculations.

Our analysis of reaction 4 suggests that $k_{4}$ should be pressureindependent and that significant products are I + OIO. Consistent with these products, Vipond and Wayne have found high yields of I atoms (around $0.5-0.8$ ) from IO + IO chemistry in a flow tube at about 2.6 mbar pressure. ${ }^{33}$ Such low pressures tend to favor dissociation over adduct stabilization. The predicted pressure-independence is consistent with the measurements by Laszlo et al. ${ }^{28}$ and Harwood et al. ${ }^{29}$ obtained in the absence of ozone. If IOIO was a major product, then $k_{4}$ would be pressure-dependent. The situation is more complicated in the presence of ozone. Himmelmann et al. ${ }^{6}$ observed OIO following the generation of $\mathrm{I}$ atoms in the presence of $\mathrm{O}_{3}$, which will react to form $\mathrm{IO}+\mathrm{O}_{2}$, and noted that $\mathrm{OIO}$ might be formed by reaction 4 or by the reaction

$$
\mathrm{IO}+\mathrm{O}_{3} \rightarrow \mathrm{OIO}+\mathrm{O}_{2}
$$

Harwood et al. ${ }^{29}$ suggested that $k_{7}$ is small, as observed by Gilles, ${ }^{24}$ which would support our proposal that reaction 4 is a source of OIO. A pressure dependence of $k_{4}$ in ozonecontaining systems has been attributed to formation of a stabilized $\mathrm{I}_{2} \mathrm{O}_{2}$ adduct. ${ }^{3,27}$ If instead $\mathrm{I}+\mathrm{OIO}$ were the main products of reaction 4 , then reaction of $\mathrm{I}$ with $\mathrm{O}_{3}$ would be expected to cycle the I atoms back to IO, so that the observed $k_{4}$ would be halved in the presence of excess $\mathrm{O}_{3}$. The ratio observed by Sander ${ }^{3}$ was around $0.56-0.83$, depending on the pressure, very roughly in line with our expectations. We cannot explain the pressure dependence observed in the presence of ozone, but we do note that Laszlo et al. ${ }^{28}$ observed complex kinetics under such conditions, and we speculate that in the presence of ozone there may be secondary chemistry which is not yet understood. 
Our interpretation of the IO self-reaction can be contrasted to measurements for $\mathrm{ClO}+\mathrm{ClO}$. In the latter case termolecular recombination dominates over bimolecular processes at pressures above 13 mbar, ${ }^{19}$ which reflects the different thermochemistry: disproportionation to $\mathrm{Cl}+\mathrm{OClO}$ is endothermic by $11.3 \pm 4.2 \mathrm{~kJ} \mathrm{~mol}^{-1},{ }^{19}$ rather than exothermic as proposed here for $\mathrm{IO}+\mathrm{IO} \rightarrow \mathrm{I}+\mathrm{OIO}$.

We point out that an alternative to reaction 5 for the reaction of I with OIO is

$$
\mathrm{OIO}+\mathrm{I}+\mathrm{N}_{2} \rightarrow \mathrm{IIO}_{2}+\mathrm{N}_{2}
$$

The higher frequencies of $\mathrm{IIO}_{2}$ lead to smaller densities of states at a given energy than for IOIO, which more than offsets the greater $\mathrm{I}-\mathrm{IO}_{2}$ adduct formation enthalpy of $75 \mathrm{~kJ} \mathrm{~mol}^{-1}$, so that $k_{8}$ is predicted to be about half $k_{5}$, at $4.0 \times 10^{-32}$ molecule ${ }^{-2}$ $\mathrm{cm}^{6} \mathrm{~s}^{-1}$. Changing the $\mathrm{I}-\mathrm{IO}_{2}$ bond strength by $\pm 15 \mathrm{~kJ} \mathrm{~mol}^{-1}$ changes $k_{8}$ by a factor of 3 . The lifetime of $\mathrm{IIO}_{2}$ with respect to the reverse of reaction 8 is predicted to be around $4 \mathrm{~s}$ at ambient conditions. This is the most stable of the $\mathrm{I}_{2} \mathrm{O}_{2}$ isomers, but is still only barely so under ambient conditions. In experiments with significant concentrations of atomic I, molecular iodine might be formed via the abstraction reactions

$$
\begin{aligned}
& \mathrm{I}+\mathrm{IOIO} \rightarrow \mathrm{I}_{2}+\mathrm{OIO} \\
& \mathrm{I}+\mathrm{IIO}_{2} \rightarrow \mathrm{I}_{2}+\mathrm{OIO}
\end{aligned}
$$

These processes potentially complete pathways for reformation of $\mathrm{I}_{2}$ from $\mathrm{I},{ }^{34}$ and our thermochemistry indicates that both are exothermic.

\section{Conclusions}

Isomers of $\mathrm{IO}_{2}, \mathrm{I}_{2} \mathrm{O}$, and $\mathrm{I}_{2} \mathrm{O}_{2}$ have been characterized by ab initio methods. For the first time, structural information is presented for these species, as well as vibrational frequencies, and their thermochemistry has been derived using G2 energies coupled with isodesmic reactions. There are no measurements of the heats of formation for these molecules, and the present work exhibits some significant differences from recent empirical estimates. The results are employed to interpret the kinetics of the $\mathrm{IO}+\mathrm{IO}$ reaction, and OIO is likely to be a significant product. Potential further reactions of I with $\mathrm{OIO}$ are also discussed.

Note Added in Proof. Cox and co-workers have recently investigated the $\mathrm{IO}+\mathrm{IO}$ reaction by time-resolved UV absorption spectroscopy and found that OIO is a significant product, with no evidence for formation of a stabilized $\mathrm{I}_{2} \mathrm{O}_{2}$ adduct. ${ }^{35}$

Acknowledgment. We thank R. A. Cox, M. K. Gilles, P. Spietz, and A. Vipond for valuable discussions and comments. This work was supported by the Air Force Office of Scientific Research, the R. A. Welch Foundation (Grant B-1174) and the UNT Faculty Research Fund. Computer time was provided by the Air Force Research Laboratory, Materials Directorate, Wright-Patterson AFB.

\section{References and Notes}

(1) Solomon, S.; Garcia, R. R.; Ravishankara, A. R. J. Geophys. Res. D 1994, 99, 20491.

(2) Solomon, S.; Burkholder, J. B.; Ravishankara, A. R.; Garcia, R. R. J. Geophys. Res. D 1994, 99, 20929.

(3) Sander, S. P. J. Phys. Chem. 1986, 90, 2194.

(4) Zolotarev, V. A.; Ishkov, D. V.; Podmar'kov, Y. P.; Frolov, M. P.; Yuryshev, N. N. Sov. J. Quantum Electron. 1991, 21, 826.

(5) Chase, M. W. J. Phys. Chem. Ref Data 1996, 25, 1297.

(6) Himmelmann, S.; Orphal, J.; Bovensmann, H.; Richter, A.; Ladstätter-Weissenmayer, A.; Burrows, J. P. Chem. Phys. Lett. 1996, 251, 330.

(7) Maier, G.; Bothur, A. Chem. Ber./Recueil 1997, 130, 179.

(8) Tapscott, R. E.; Skaggs, S. R.; Dierdorf, D. In Halon Replacements: Technology and Science; Tsang, W.; Miziolek, A. W., Eds.; ACS Symp. Ser. 611; American Chemical Society: Washington, DC, 1995; Chapter 14

(9) Misra, A.; Sees, J.; Hall, L.; Levy, R. A.; Zaitsev, V. B.; Aryusook, K.; Ravindranath, C.; Sigal, V.; Kesari, S.; Rufin, D. Mater. Lett. 1998, 34,415 .

(10) Fracassi F.; d'Augustino, R.; Stenardo, M.; Atzei, L. R.; Illuzi, F. Environmental Impact of Fluorocarbon and Iodofluorocarbon Containing Glow Discharges for $\mathrm{SiO}_{2}$ Etching. Proceedings of the Fourth International ESH Conference; Milan, Italy, 1997; Vol. 1.

(11) Frisch, M. J.; Trucks, G. W.; Schlegel, H. B.; Gill, P. M. W.; Johnson, B. G.; Robb, M. A.; Cheeseman, J. R.; Keith, T. A.; Petersson, G. A.; Montgomery, J. A.; Raghavachari, K.; Al-Laham, M. A.; Zakrzewski, V. G.; Ortiz, J. V.; Foresman, J. B.; Cioslowski, J.; Stefanov, B. B.; Nanayakkara, A.; Challacombe, M.; Peng, C. Y.; Ayala, P. Y.; Chen, W.; Wong, M. W.; Andres, J. L.; Replogle, E. S.; Gomperts, R.; Martin, R. L.; Fox, D. J.; Binkley, J. S.; Defrees, D. J.; Baker, J.; Stewart, J. J. P.; HeadGordon, M.; Gonzalez, C.; Pople, J. A. GAUSSIAN 94; Gaussian, Inc. Pittsburgh, PA, 1995

(12) Curtiss, L. A.; Raghavachari, K.; Trucks, G. W.; Pople, J. A. J. Chem. Phys. 1991, 94, 7221.

(13) Glukhovtsev, M. N.; Pross, A.; McGrath, M. P.; Radom, L. J. Chem Phys. 1995, 103, 1878.

(14) Misra, A.; Marshall, P. J. Chem Soc., Faraday Trans. 1997, 93, 3301.

(15) Gurvich, L. V.; Veyts, I. V.; Alcock, C. B., Eds. Thermodynamic Properties of Individual Substances Vol. I, 4th ed.; Hemisphere: New York, 1989.

(16) Curtiss, L. A.; Raghavachari, K.; Pople, J. A. J. Chem. Phys. 1995, $103,4192$.

(17) Gilles, M. K.; Polak, M. L.; Lineberger, W. C. J. Chem. Phys. 1992, 96, 8012 .

(18) Bedjanian, Y.; Le Bras, G.; Poulet, G. J. Phys. Chem. A 1997, 101 4088 .

(19) DeMore, W. B.; Sander, S. P.; Golden, D. M.; Hampson, R. F.; Kurylo, M. J.; Howard, C. J.; Ravishankara, A. R.; Kolb, C. E.; Molina, M. J. Chemical Kinetics and Photochemical Data for Use in Stratospheric Modeling, Evaluation Number 12, JPL Publication 97-4; Jet Propulsion Laboratory, California Institute of Technology, Pasadena, CA, 1997.

(20) Lias, S. G.; Bartmess, J. E.; Liebman, J. F.; Holmes, J. L.; Levin, R. D.; Mallard, W. G. J. Phys. Chem. Ref Data 1988, 17; Suppl. 1, GasPhase Ion and Neutral Thermochemistry.

(21) Berry, R. J.; Yuan, J.; Misra, A.; Marshall, P. J. Phys. Chem. A $1998,102,5182$.

(22) Hassanzadeh, P.; Irikura, K. K. J. Phys. Chem. A. 1997, 101, 1580.

(23) Baulch, D. L.; Duxbury, J.; Grant, S. J.; Montague, D. C. J. Phys Chem. Ref. Data 1981, 10; Suppl. 1, Evaluated Kinetic Data for HighTemperature Reactions Vol. 4.

(24) Gilles, M. K. Personal communication, 1998

(25) Clyne, M. A. A.; Cruse, H. W. Trans. Faraday Soc. 1970, 66, 2227.

(26) Cox, R. A.; Coker, G. B. J. Phys. Chem. 1983, 87, 4478.

(27) Jenkin, M. E.; Cox, R. A. J. Phys. Chem. 1985, 89, 192.

(28) Laszlo, B.; Kurylo, M. J.; Huie, R. E. J. Phys. Chem. 1995, 99, 11701

(29) Harwood, M. H.; Burkholder, J. B.; Hunter, M.; Fox, R. W.; Ravishankara, A. R. J. Phys. Chem. A. 1997, 101, 853.

(30) Stickel, R. E.; Hynes, A. J.; Bradshaw, J. D.; Chameides, W. L.; Davis, D. D. J. Phys. Chem. 1988, 92, 1862

(31) Dean, A. M. J. Phys. Chem. 1985, 89, 4600.

(32) Westmoreland, P. R. BI_QRRK computer program, 1993.

(33) Vipond, A. Personal communication, 1998

(34) Spietz, P. Personal communication, 1998.

(35) Bloss, W. J.; Rowley, D. M.; Cox, R. A.; Jones, R. L. Kinetic Studies of Iodine Oxide Reactions of Atmospheric Importance. 15th International Symposium on Gas Kinetics, Bilbao, Spain, 1998; Posters A45/ A46. 